\title{
Barcelona a través de las noticias de prime time de la televisión pública de Corea del sur
}

\section{Barcelona on the prime time news of South Korean public television}

\author{
SIN GYU KANG \\ ORCID https://orcid.org/0000-0001-7864-6328 \\ Universidad de Girona, España \\ Facultad de Turismo \\ Silvia Espinosa Mirabet \\ ORCID http://orcid.org/0000-0002-8304-5882 \\ Universidad de Girona \\ Facultad de Turismo
}

\section{Resumen}

La imagen turística de una ciudad es clave para presentarse al mundo y que se construyan internacionalmente sus rasgos definitorios. De este modo, la relación entre percepción e imagen turística son conceptos fundamentales para atraer turistas a un destino determinado. El objetivo del presente artículo es analizar cómo las noticias de la televisión coreana contribuyen a crear una imagen de Barcelona en Corea del Sur. La investigación se realizará a través de un análisis de contenido de los informativos de prime time. Así, hemos observado durante un periodo de diez años (2010-2019) las noticias con más audiencia de las secciones de política, economía, internacional, sociedad, cultura y deporte de las tres televisiones públicas de Corea del Sur con mayor impacto en la sociedad coreana: $K B S, M B C$ y SBS. Los resultados evidencian como la mayoría de las noticias transmitidas sobre Barcelona se adscriben a cultura y deporte mostrando un tono positivo mientras que las de política e internacional tienen un tono mayoritariamente negativo. Asimismo, las secciones con más

\section{Abstract}

The tourist image of a city is the key to presenting itself to the world and for its defining features to be built internationally. Thus, the relationship between perception and tourist image are fundamental concepts to attract tourists to a specific destination. The objective of this article is to analyze the image of Barcelona in South Korea through the analysis of Korean public television news. The investigation will be carried out through a content analysis of the prime time newscasts. We have observed the news for a period of ten years (2010-2019) with the most audience from the sections of politics, economy, international, society, culture and sport of the three public television stations in South Korea with the greatest impact on Korean society: KBS, $M B C$ and SBS. The results show that most of the news broadcast about Barcelona is ascribed to culture and sport, keeping a positive tone, while the political and international news have mostly a negative tone. Likewise, the sections with the most televised news about the Catalan capital are sports, international and politics. 
noticias televisadas sobre la capital catalana son de deporte, internacional y política.

Palabras claves: Barcelona, Televisión pública, Corea del Sur, Noticia de televisión, Imagen de Barcelona, Prime time.
Keywords: Barcelona; Public television; South Korea; Television news; Image of Barcelona; Prime time.

\section{Introducción}

En la última década, el turismo surcoreano ha aumentado de forma acelerada en España. En el año 2009 llegaron al país 25.000 turistas procedentes de Corea del Sur (Rovira, 2017), cifra que aumentó significativamente en cinco años, como lo muestran los datos del Instituto Nacional de Estadística (INE, 2019), donde se contabilizan, para el año 2014, 167 mil visitantes y ha continuado incrementándose, hasta llegar a las 630 mil personas para el año 2019. Según La Vanguardia (2014), los coreanos descubrieron Barcelona más en profundidad a través de programas televisivos como Ggot Boda Halbe (Los abuelos son mejores que las flores) de la cadena privada TVN que ocupó el primer lugar del ranquin de audiencias durante cuatro semanas consecutivas en Corea del Sur'.

Además, la televisión coreana emite con frecuencia reportajes o programas ${ }^{2}$ como el citado anteriormente, por ejemplo, sobre ciudades con atractivos turísticos (Han, 2018). Sus rutinas de producción consisten en viajar directamente al país en el que se desea indagar más a fondo para realizar el programa.

La imagen del destino es reconocida como una construcción importante que influye en la toma de decisiones de los turistas y sus comportamientos futuros (Zhang, Xu, Leung, y Cai, 2016). En el caso de Corea del Sur, se entiende que una de las razones de la popularidad de Barcelona es el efecto de los medios.

La literatura académica explica el efecto de los medios de comunicación y también la percepción que generan en las personas (Aranda et al, 2018). Entre ellos, tal como dice Liu et al. (2019), los medios de comunicación desempeñan un papel importante en la toma de decisiones sobre dónde ir, dónde alojarse y qué hacer cuando se viaja. La tendencia del desarrollo del turismo muestra que la percepción de la sociedad sobre el turismo está cambiando debido al efecto de los medios (Jacobsen y Munar, 2012). Katlu et al. (2018) señalan que los recientes sucesos mundiales y regionales, incluidos el terrorismo, las epidemias y los disturbios políticos, al ser difundidos por los medios afectan a la percepción que las personas tienen de sus destinos turísticos.

Como se mencionó anteriormente, la imagen que tiene un destino se reconoce como un antecedente importante en el comportamiento futuro de un posible turista. Sin embargo, lo cierto es que la industria turística catalana no tiene estudios que describan la imagen de Barcelona en Corea del Sur. Precisamente en este punto radica la relevancia de este trabajo, cuyo objetivo es analizar qué imagen se tiene Barcelona en Corea del Sur a través de las noticias de prime time de los informativos de la televisión pública. La investigación realizará un análisis de contenido de los noticiarios con mayor audiencia, similar al realizado por autores como McCracken (1987). Así, hemos observado durante un periodo de diez años (2010-2019) las noticias de prime time (19:00-22:00) de las tres televisiones públicas de Corea del Sur: $K B S, M B C$ y $S B S^{3}$. 


\section{Noticias de televisión y formación de imagen de destino}

Los medios influyen en la percepción de las noticias a partir, por ejemplo, de la agenda setting y el framing (Hamborg et al., 2019). La agenda setting se refiere a la capacidad de los editores de seleccionar noticias que acabarán formando la terna de temas de actualidad que verán la luz a través de todos los medios y serán motivo de debates, de aperturas de espacios informativos audiovisuales e incluso serán los temas de discusión de la opinión pública (McCombs, 2015). La teoría de agenda setting sostiene que los temas que parecen relevantes en los medios influyen en forma destacada en la opinión pública (Rubio García, 2014). Además, esta teoría afirma que la importancia que los medios dan a los atributos de los temas influye en la importancia que estos atributos tienen en la opinión pública a la hora de evaluarlos. Esta agenda setting afecta la comprensión, tanto a nivel cognitivo como afectivo (Capriotti, 2012). Por su parte, el framing hace referencia a una idea central que organiza el contenido informativo, dotándole de un contexto y sugiriendo el tema tratado mediante el uso de técnicas de selección, énfasis, exclusión y elaboración (Sabrina Koziner, 2013).

Las noticias de televisión, a diferencia de otros medios, no permiten a la audiencia controlar el orden o la velocidad del procesamiento de la información. Además, la audiencia solo puede seleccionar el canal, no controlarlo, son los creadores de la noticia quienes lo controlan (Chipp y Chakravorty, 2016). Por tanto, la composición de la realidad cambia según el tono con que se informe mediante las noticias de televisión, y esta composición se extiende no solo a cada individuo sino también a la sociedad en su conjunto formando respuestas sociales.

La característica intrínseca de las noticias de televisión es que dan su información a través de recursos audiovisuales en mucha mayor medida que el resto de los medios. La televisión muestra imágenes con escenas y sonidos vívidas, y proporciona otros elementos visuales de soporte para la información (Maite, 2016).

Cuando se obtiene información sin recurrir a medios audiovisuales es necesario comprender el significado escrito, en cambio, la utilización de videos permite mostrar de forma implícita el mensaje que se desea transmitir y eso redunda en los aspectos clave del mensaje y en un ahorro de tiempo. Y, por supuesto, ejerce su influencia incluso sobre los espectadores involuntarios. Como resultado, las noticias de televisión van más allá de proporcionar información, pues actúan de manera amplia y rápida (Montemayor Ruiz, 2013: 20).

Las propias características de la televisión por su condición de emisora de elementos de comunicación audiovisual, condicionan también la selección de los mensajes que se emiten en los informativos de las diferentes cadenas. Por ello, la inclusión de imágenes en una noticia implica que el medio de comunicación le otorga un tratamiento de mayor importancia y calidad informativa frente aquellas noticias que tan solo incluyen alocuciones. Según Lee et al. (2013), las imágenes realistas estimulan la generación de imágenes mentales. Por lo tanto, los medios afectan la percepción de manera diferente dependiendo de si llevan video o no.

Asimismo, la televisión es un medio que somete la organización y el tratamiento de los hechos a un tiempo breve (Morales Colipe, 2016). Según Cebrián Herreros (2004: 186) "Una duración inferior supone una menor importancia del hecho (...) por el contrario, una duración superior otorga un relieve mayor a los hechos y, en consecuencia, permite una elección más amplia y un tratamiento más profundo". 
Hablando de formación de la imagen de destino, la imagen está formada por dos fuerzas mayores, dos factores; factores estímulo y factores personales (Beerli y Martín, 2004). Los factores estímulo son aquellos que provienen de estímulos externos y objetos físicos y también de experiencias previas. Entre estos estímulos externos, se encuentra la experiencia previa, que juega un papel muy importante en la formación de la imagen (Gutiérrez y Bosque, 2010).

Sobre estímulos externos, Gartner (1993: 472) determina la existencia de cuatro tipos de agentes de formación de la imagen turística: agentes inductivos (organizaciones turísticas, empresas turísticas locales/ tour operadores, agentes de viajes), agentes inductivos encubiertos (líderes de opinión/ periodistas, reportajes, etc.), agentes autónomos (personas individuales u organizaciones que producen artículos, reportajes, televisión, noticias, etc.) y agentes orgánicos (personas que han viajado al destino).

En base a la teoría expuesta en con relación a la elaboración de imágenes sobre el lugar del destino, por un lado, expone un análisis inducido encubierto de los estímulos externos, puesto que el análisis se basará en la observación de la información que la televisión coreana emite en Corea. Cabe considerar que los medios muchas veces se alimentan tanto de los agentes autónomos como de los agentes orgánicos.

\section{Metodología}

\subsection{Diseño de investigación}

En esta investigación se han escogido las tres televisiones públicas de Corea del Sur con mayor impacto en la sociedad coreana según la Korea Press Foundation: KBS, MBC y SBS. El periodo temporal del análisis se extiende durante diez años, concretamente desde el 1 de enero de 2010 al 31 de diciembre de 2019. Además, se han establecido seis categorías de análisis de las noticias emitidas durante el período seleccionado siguiendo la división de secciones de contenido, realizada por las propias televisiones: política, economía, internacional, sociedad, cultura y deportes.

Además, se ha analizado el tono de los mensajes transmitidos sobre Barcelona y se han clasificado según sean positivos, negativos o neutrales. El criterio que seguiremos para definir lo que es un mensaje positivo, negativo o neutral tendrá además el refuerzo de la conceptualización de lo que es una mala noticia según el estudio de Christian Schemer (2012) sobre la influencia de los medios de comunicación. El autor afirma que una mala noticia es toda aquella información nueva que altera de forma negativa la visión sobre un tema. Podemos trasladar este concepto a nuestra clasificación de buenos y malos mensajes, considerando malos mensajes aquellos que alteran de forma negativa la imagen de algo para la persona que lo recibe, y del lado contrario, consideraremos buenos los mensajes que alteran de forma positiva la visión sobre un asunto o lugar. Consideraremos neutrales aquellos mensajes que no proporcionan ninguna alteración en la imagen que se construye en la percepción de las personas que los reciben.

\subsection{Codificación de datos y medición de fiabilidad}

Se considera que un método de investigación es fiable cuando su aplicación en reiteradas ocasiones a los mismos datos, no altera los resultados y se obtiene la misma respuesta. $Y$ este aspecto es fundamental para validar los resultados (Alonso et al., 2012: 35). En ese sentido, es importante tener presente que la fiabilidad es un factor clave del análisis de contenido. De igual modo, Neuendorf (2002: 141) sostiene que, sin establecer la fiabilidad, "las medidas del análisis de contenido no sirven". 
Así, en este estudio, se trabajó con dos codificadores diferentes que analizaron la misma noticia de la televisión y compararon sus resultados para medir la fiabilidad y la coincidencia en el tono de las informaciones sobre Barcelona. La codificación de datos se realizó de acuerdo con el siguiente procedimiento, tal como recomienda Neuendorf (2002):

1. Se creó una hoja de codificación y se decidieron las directrices de codificación.

2. Se procedió al primer análisis y se midió la fiabilidad de los dos codificadores. Al ser inferior al $85 \%$, (nivel confiable) entonces se continua con el proceso y se codifica la muestra completa, tal como recomienda Neuendorf (2002). Par él, una fiabilidad de 0,6 o más se considera alta. La fiabilidad de este estudio fue de 0,88 . Esto demuestra una alta fiabilidad.

3. Se valoraron en una reunión, las discrepancias entre los investigadores y se procedió con toda la muestra.

En este estudio, la fiabilidad del contenido se ha medido utilizando el coefficient of reliability de Holsti (1969), que es uno de los métodos para medir la fiabilidad del análisis de contenido.

\section{Discusión de los resultados}

Para recoger las muestras y realizar este estudio se utilizó un servicio de reproducción de noticias en la página de inicio de Internet de cada una de las emisoras de TV que son nuestras unidades de análisis. En este sitio web, se buscaron informaciones con la palabra clave "Barcelona". La búsqueda arrojó 2.523 noticias en $K B S, 2.645$ noticias en $M B C, 3.270$ noticias de SBS. En total se obtuvieron 8.438 informaciones. Pero, puesto que estas informaciones son todas las noticias que contienen la palabra "Barcelona", se volvieron a examinar, incluyendo solamente las noticias de prime time (19:00-22:00). Durante el período de diez años del análisis, la mayoría de las noticias relacionadas con Barcelona en la televisión no trataban contenidos informativos sobre la ciudad de Barcelona sino sobre personas, marcas o asuntos de Corea del Sur que se presentaban o tenían alguna vinculación con Barcelona, siendo la ciudad sólo el contexto.

Por ejemplo, el contenido de la noticia "Samsung Galaxy S9 lanzado en Barcelona (26/02/2018)" trataba sobre Samsung Galaxy S9. Igualmente, ocurre con el artículo titulado "Kumho Tires, F1 de Barcelona pasa con éxito la prueba" (02/09/2013) y "Lee Seung-woo juegan en el equipo B del Barcelona" (07/07/2015), "Jung-Hyun participa en el Barcelona Open" (01/05/2017), "Lee Nurie, $1^{\text {er }}$ lugar en el Concurso de Danza de Barcelona" (21/05/2016) o "Park Tae-hwan no asiste a los campeonatos mundiales de natación de Barcelona"4 (12/04/2013).

Por lo tanto, y a partir de esta óptica, se analizará en las tres televisiones el concepto "Barcelona" en las noticias, la frecuencia con la que la televisión emite contenidos sobre Barcelona y el tono de las noticias. Se observará además si estas noticias incluyen vídeos o no y la duración de cada información. Con todos estos datos se podrá obtener una clara percepción sobre el peso de Barcelona en las tres televisiones públicas coreanas y cómo ello podría contribuir a crear una imagen de la ciudad condal como destino turístico apetecible.

En la cadena $K B S$ se han analizado una serie de 107 noticias. Son las únicas noticias que no repiten contenido y que no tratan Barcelona como un contexto de la información, sino como el sujeto de la misma. Significan una cantidad más que suficiente para darle validez. En la siguiente tabla podemos ver su contenido según las seis secciones establecidas (política, economía, internacional, sociedad, cultura y deporte). 
Tabla 1. Análisis de la frecuencia de las noticias en la televisión KBS (2010-2019).

\begin{tabular}{|c|c|c|c|c|c|c|c|c|c|c|c|}
\hline & 2010 & 2011 & 2012 & 2013 & 2014 & 2015 & 2016 & 2017 & 2018 & 2019 & Total \\
\hline Política & 0 & 0 & 1 & 0 & 0 & 0 & 1 & 6 & 3 & 7 & 18 \\
\hline Economía & 0 & 0 & 1 & 0 & 0 & 1 & 0 & 1 & 1 & 1 & 5 \\
\hline Sociedad & 0 & 1 & 1 & 0 & 0 & 0 & 1 & 2 & 1 & 1 & 7 \\
\hline Cultura & 1 & 0 & 0 & 1 & 0 & 0 & 0 & 2 & 1 & 0 & 5 \\
\hline Internacional & 0 & 1 & 1 & 2 & 2 & 1 & 1 & 6 & 3 & 8 & 25 \\
\hline Deporte & 2 & 2 & 4 & 6 & 4 & 6 & 4 & 6 & 5 & 8 & 47 \\
\hline Total & 3 & 4 & 8 & 9 & 6 & 8 & 7 & 23 & 14 & 25 & 107 \\
\hline
\end{tabular}

Fuente: elaboración propia.

Como puede observarse en la Tabla 1, la mayor parte de las noticias se relacionan con el deporte en Barcelona (43,9\%), seguidas por las noticias sobre internacional $(23,3 \%)$ y política $(16,8 \%)$. En el lado contrario, las temáticas de menor frecuencia fueron las que tratan sobre economía $(4,6 \%)$ y cultura $(4,6 \%)$. En el caso de las noticias con la temática más frecuente, los deportes, casi todas están relacionadas con el fútbol profesional, un ámbito muy asociado a Barcelona. En definitiva, deportes, internacional y política suponen más de la mitad de las noticias $(84,1 \%)$ transmitidas en $K B S$ vinculados a Barcelona.

A continuación, se puede observar la Tabla 2 que presenta el análisis del tono de la información en las noticias de KBS (2010-2019). Según el análisis, hay muchas noticias positivas en deporte (72,3\%), cultura (60\%), sociedad (42,9\%) y noticias negativas en internacional (64\%), política $(61,1 \%)$ y economía (40\%).

Tabla 2. Análisis del tono en las noticias en la televisión KBS (2010-2019).

\begin{tabular}{|c|c|c|c|}
\hline & Positivo & Negativo & Neutro \\
\hline Política & $5,6 \%$ & $61,1 \%$ & $33,3 \%$ \\
\hline Economía & $20,0 \%$ & $40,0 \%$ & $40,0 \%$ \\
\hline Sociedad & $42,9 \%$ & $14,3 \%$ & $42,9 \%$ \\
\hline Cultura & $60,0 \%$ & $0,0 \%$ & $40,0 \%$ \\
\hline Internacional & $8,0 \%$ & $64,0 \%$ & $28,0 \%$ \\
\hline Deporte & $72,3 \%$ & $4,3 \%$ & $23,4 \%$ \\
\hline
\end{tabular}

Fuente: elaboración propia.

Y finalmente se incluye una tabla más para esta cadena televisiva (Grafico 1). Aquí se detallan las duraciones de los temas analizados y si estos incluyen imágenes o son sólo alocuciones de un presentador mirando a cámara, cosa que denotaría un tratamiento de menor importancia y calidad informativa, tal como se ha expresado en el marco teórico de este trabajo. En la televisión $K B S$, el 96\% de las noticias incluyeron video, y el $81 \%$ de las noticias de televisión ocuparon espacios de entre 30 y 60 segundos. 


\section{Grafico 1: Tipos y duraciones de los temas analizados KBS (2010-2019).}

$4 \%$

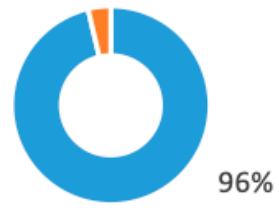

- con video $\quad$ sin video
[]-

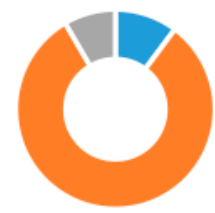

[] -

11 casos

[] -

87 casos

- más de $10 \mathrm{~s}$ - más de 30s ㅍ más de 60s

Fuente: elaboración propia.

La segunda televisión analizada es la $M B C$. En este caso, en los diez años estudiados, se transmitieron un total de 87 noticias con contenidos relacionados con Barcelona. Estos 87 artículos han sido seleccionados de las 2.645 noticias que se transmitieron en prime time en la MBC. Así, el deporte es también la temática más abundante, representando el 40,4\% de las noticias. Las siguientes temáticas en popularidad son de la sección de política $(19,8 \%)$ y de internacional (16,7\%). Por el contrario, las noticias con menor frecuencia de transmisión son de sociedad $(6,8 \%)$ y economía $(2,2 \%)$. Como puntualización, hay que añadir que, debido a los atentados de Cataluña ${ }^{5}$ y del conflicto por la independencia, en 2017 y 2019 han crecido exponencialmente las noticias aparecidas en televisión, en comparación con otros años. Se pueden observar los datos comentados en la Tabla 3:

Tabla 3. Análisis de la frecuencia de las noticias en la televisión MBC (2010-2019).

\begin{tabular}{|c|c|c|c|c|c|c|c|c|c|c|c|}
\hline & 2010 & 2011 & 2012 & 2013 & 2014 & 2015 & 2016 & 2017 & 2018 & 2019 & Total \\
\hline Política & 2 & 2 & 2 & 1 & 2 & 2 & 1 & 6 & 2 & 6 & 26 \\
\hline Economía & 0 & 0 & 0 & 0 & 0 & 0 & 1 & 1 & 0 & 1 & 3 \\
\hline Sociedad & 0 & 0 & 1 & 0 & 0 & 2 & 1 & 2 & 1 & 2 & 9 \\
\hline Cultura & 1 & 2 & 1 & 1 & 2 & 1 & 3 & 3 & 2 & 2 & 18 \\
\hline Internacional & 0 & 1 & 2 & 1 & 2 & 1 & 2 & 5 & 2 & 6 & 22 \\
\hline Deporte & 4 & 5 & 6 & 5 & 6 & 5 & 5 & 6 & 4 & 7 & 53 \\
\hline Total & 7 & 10 & 12 & 8 & 12 & 11 & 13 & 23 & 11 & 24 & 131 \\
\hline
\end{tabular}

Fuente: elaboración propia.

A continuación, observemos la Tabla 4 que presenta el análisis del tono de las noticias transmitidas en la televisión MBC (2010-2019). La mayoría de noticias positivas sobre Barcelona se refieren al ámbito de la cultura (72,2\%), al deporte $(62,3 \%)$ y a sociedad (55,6\%), mientras que en economía (33,3\%), política $(7,7 \%)$ e internacional (4,5\%), disminuyen los índices de noticias positivas. 
Tabla 4. Análisis del tono en las noticias en la televisión MBC (2010-2019).

\begin{tabular}{|c|c|c|c|}
\hline & Positivo & Negativo & Neutro \\
\hline Política & $7,7 \%$ & $61,5 \%$ & $30,8 \%$ \\
\hline Economía & $33,3 \%$ & $33,3 \%$ & $33,3 \%$ \\
\hline Sociedad & $55,6 \%$ & $11,1 \%$ & $33,3 \%$ \\
\hline Cultura & $72,2 \%$ & $0,0 \%$ & $27,8 \%$ \\
\hline Internacional & $4,5 \%$ & $63,6 \%$ & $31,8 \%$ \\
\hline Deporte & $62,3 \%$ & $3,8 \%$ & $34,0 \%$ \\
\hline
\end{tabular}

Fuente: elaboración propia.

Sobre la incorporación de imágenes en las noticias de Barcelona en esta cadena, así como sobre sus duraciones (Grafico 2) hay que añadir que en la $M B C$ la mayoría (95\%) de temas llevaban vídeos explicando la información y la mayoría (84\%) de las duraciones de las mismas fueron entre los 30 segundos y los 60 segundos en la noticia de prime time

Grafico 2: Tipos y duraciones de los temas analizados MBC (2010-2019).

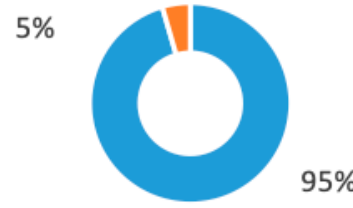

- con video $=$ sin video

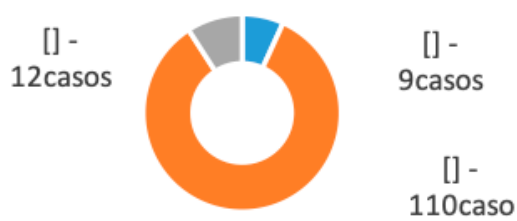

- más de 10 s = más de 30s a más đe 60s

Fuente: elaboración propia.

La tercera televisión analizada es la SBS. En este caso tenemos 127 noticias. Estas 127 noticias han sido seleccionadas de las 3.270 noticias que se transmitieron en los informativos de prime time de la SBS. En este caso el deporte (44\%), la política $(20,4 \%)$, internacional $(19,6 \%)$ y cultura $(7 \%)$ son los temas más vinculados a Barcelona seguidos de las noticias de sociedad (6,2\%) y de economía (2,3\%). En el caso de $S B S$, la suma de deporte y política constituye más de la mitad de las noticias transmitidas, concretamente un $64,5 \%$.

Tabla 5. Análisis de la frecuencia de las noticias en la televisión SBS (2010-2019).

\begin{tabular}{|c|c|c|c|c|c|c|c|c|c|c|c|}
\hline & $\mathbf{2 0 1 0}$ & $\mathbf{2 0 1 1}$ & $\mathbf{2 0 1 2}$ & $\mathbf{2 0 1 3}$ & $\mathbf{2 0 1 4}$ & $\mathbf{2 0 1 5}$ & $\mathbf{2 0 1 6}$ & $\mathbf{2 0 1 7}$ & $\mathbf{2 0 1 8}$ & $\mathbf{2 0 1 9}$ & Total \\
\hline Política & 1 & 1 & $\mathbf{3}$ & $\mathbf{1}$ & $\mathbf{2}$ & $\mathbf{1}$ & $\mathbf{1}$ & 6 & 3 & 7 & 26 \\
\hline Economía & 0 & 0 & 0 & 1 & 0 & 0 & 0 & 1 & 1 & 0 & 3 \\
\hline Sociedad & 1 & 1 & 0 & 1 & 1 & 0 & 1 & 1 & 1 & 1 & 8 \\
\hline Cultura & 2 & 1 & 1 & 1 & 1 & 1 & 0 & 1 & 1 & 0 & 9 \\
\hline Internacional & 1 & 0 & 1 & 1 & 1 & 2 & 2 & 8 & 3 & 6 & 25 \\
\hline Deporte & 6 & 5 & 4 & 5 & 5 & 6 & 6 & 5 & 5 & 9 & 56 \\
\hline Total & 11 & 8 & 9 & 10 & 10 & 10 & 10 & 22 & 14 & 23 & 127 \\
\hline
\end{tabular}

Fuente: elaboración propia. 
En la siguiente tabla observaremos el análisis del tono de las noticias transmitidas en la televisión SBS (2010-2019). En el caso de la SBS, hay un porcentaje mayor de noticias positivas en deporte $(71,4 \%)$, cultura $(55,6 \%)$ y sociedad (50\%). Al contrario, hay un porcentaje mayor de noticias negativas en política $(61,5 \%)$ e internacional (68\%).

Tabla 6. Análisis del tono en las noticias en la televisión SBS (2010-2019).

\begin{tabular}{|c|c|c|c|}
\hline & Positivo & Negativo & Neutro \\
\hline Política & $11,5 \%$ & $61,5 \%$ & $26,9 \%$ \\
\hline Economía & $0,0 \%$ & $33,3 \%$ & $66,7 \%$ \\
\hline Sociedad & $50,0 \%$ & $12,5 \%$ & $37,5 \%$ \\
\hline Cultura & $55,6 \%$ & $11,1 \%$ & $33,3 \%$ \\
\hline Internacional & $12,0 \%$ & $68,0 \%$ & $20,0 \%$ \\
\hline Deporte & $71,4 \%$ & $3,6 \%$ & $25,0 \%$ \\
\hline
\end{tabular}

Fuente: elaboración propia.

Finalmente hay que añadir (Grafico 3) que en la SBS la mayoría (97\%) de temas llevaban vídeos explicando la información y las duraciones de las mismas oscilaron entre los 30 segundos y los 60 segundos (86\%) en el prime time.

\section{Grafico 3: Tipos y duraciones de los temas analizados SBS (2010-2019).}

$3 \%$

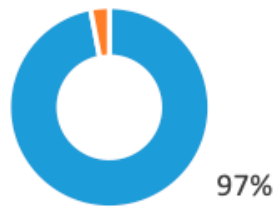

- con video = sin video

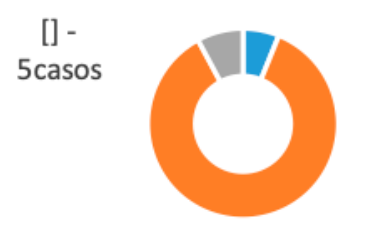

[] -

4 casos

[] -

118 cas

OS

- más de $10 \mathrm{~s}$ - más de $30 \mathrm{~s}$ - más de $60 \mathrm{~s}$

Fuente: elaboración propia.

Así pues y a modo de resumen, tal como se muestra en la Tabla 7, la imagen de Barcelona en las noticias de las tres televisiones públicas coreanas es, en general, positiva. Así, tenemos el mayor porcentaje de noticias positivas en el deporte $(68,6 \%)$ y la cultura $(65,6 \%)$.

Tabla 7. Suma del análisis del tono de las noticias transmitidas en las tres televisiones (2010-2019).

\begin{tabular}{|c|c|c|c|}
\hline & Positivo & Negativo & Neutro \\
\hline Política & $8,6 \%$ & $61,4 \%$ & $30,0 \%$ \\
\hline Economía & $18,2 \%$ & $36,4 \%$ & $45,5 \%$ \\
\hline Sociedad & $50,0 \%$ & $12,5 \%$ & $37,5 \%$ \\
\hline Cultura & $65,6 \%$ & $3,1 \%$ & $31,3 \%$ \\
\hline Internacional & $8,3 \%$ & $65,3 \%$ & $26,4 \%$ \\
\hline Deporte & $68,6 \%$ & $3,8 \%$ & $27,6 \%$ \\
\hline
\end{tabular}

Fuente: elaboración propia. 
A excepción de la opinión neutral, los ámbitos en el que las noticias negativas predominan son en política e internacional, y se relacionan con la situación política y la noticia del robo a una funcionaria coreana en Cataluña ${ }^{6}$. En este sentido y sobre la situación política, hay que destacar que cuando la prensa coreana muestra una imagen más negativa es en el momento en que emite informaciones sobre el movimiento independentista que es mostrado como una especie de caos social, transmitido por imágenes impactantes (Foto 1)7. Son las imágenes más espectaculares de todas las noticias que se han analizado.

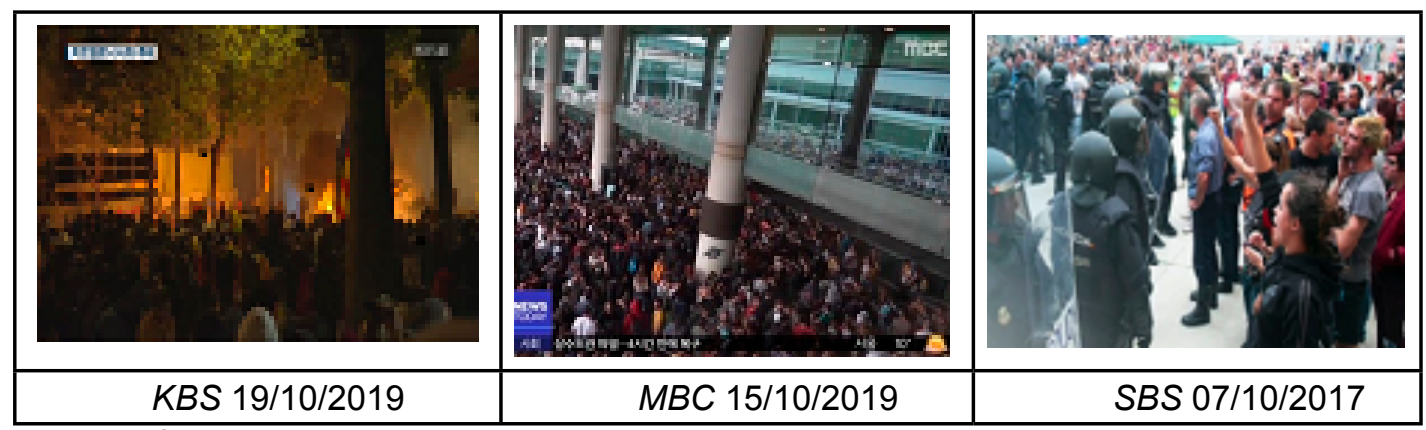

Foto 1: Imágenes de tres televisiones transmitidas en Corea del Sur

Fuente: elaboración propia con datos de $K B S, M B C, S B S$.

Acerca de las noticias de internacional, hay que añadir que son las que más incluyen informaciones sobre sucesos. Así, a los incidentes terroristas ya mencionados, cabe destacar también en este ámbito, el reciente y ya referido atraco de un alto cargo de Corea del Sur en Barcelona. Por otro lado, la cultura $(3,1 \%)$ y los artículos deportivos $(3,8 \%)$ casi no transmiten mensajes negativos a los lectores, mostrando la mayoría de las noticias mensajes positivos.

\section{Conclusiones}

Según los análisis mencionados, las imágenes positivas sobre Barcelona no van más allá del deporte o la cultura y tienen poca relación con la política o el área internacional. La mayoría de los coreanos que se informan a través de las noticias objeto de este estudio, sólo perciben Barcelona como un lugar de festivales y fútbol. Así, los temas culturales son los más comentados en las noticias coreanas. En cuanto a su temática abarcan una gran variedad: el arte, la arquitectura, los viajes o la cultura de la vida. Se pueden encontrar titulares como "Viaje a Barcelona", "Viaje a Gaudí", "Comida catalana", "200 años de una torre humana tradicional (Castells)", "Sagrada Familia se completará en 2026", "Mundo artístico de Miró" y "Museo Picasso". La mayoría de estas noticias culturales son de contenido positivo y casi ninguna (3,1\%) de ellas transmite mensajes negativos. En cuanto a los artículos deportivos, la mayoría de las tres televisiones analizadas emiten noticias relacionadas con el fútbol y transmiten un mensaje positivo, como, por ejemplo, los titulados "Título del Campeonato del FC Barcelona", "Sueño, la Liga española", "Messi 50 goles en el FC Barcelona" o "Aprender en la Masía".

Sin embargo, la economía de Cataluña representa el 19,14\% del total de la economía española (La Vanguardia, 2019) y Barcelona se ha situado en el primer puesto del ranking mundial de congresos internacionales, según el barómetro de la Asociación Internacional de Congresos y Convenciones (ICCA, 2018), pero este importante aspecto no es especialmente relevante en las informaciones analizadas en este trabajo. En los artículos sobre economía encontramos temas como "Vuelo directo Barcelona a Seúl", 
"Mercado tradicional en Barcelona", "Barcelona recesión económica" o "Compartir el fracaso en BarceIona". Un $36,4 \%$ de los mensajes económicos son negativos y un $18,2 \%$ son mensajes positivos. Por otro lado, sí que se ha observado que gran parte de las noticias de las televisiones públicas (KBS, MBC y SBS) destacan temas de política e internacional.

Así pues, en el ámbito de la política se transmiten noticias como "Cataluña por la independencia", "Voto de Cataluña", "Manifestación de la independencia catalana", o "Manifestación contra los recortes". Un $61,4 \%$ de las noticias de este campo transmiten imágenes negativas a los espectadores coreanos. En las noticias de la sección internacional, se observa como la mayoría de temas tratan sobre "Fallecimiento de un alto funcionario de Corea del Sur en Barcelona" y sobre "Terrorismo en Barcelona". En este caso también, un $65,3 \%$ contienen mensajes negativos.

Los reportajes relacionados con los temas de las secciones de sociedad incluyen las noticias como "Problema del envejecimiento de la población de Barcelona", "Gente de Barcelona", "Modelo de éxito cooperativo", "Ladrón de turistas", "38 grados de Barcelona" y "Cómo vivir felizmente". En esta sección el mensaje negativo ocupa el $12,5 \%$ de las noticias y el mensaje positivo es superior, situándose en un $50 \%$. Por lo tanto, teniendo en cuenta la dimensión afectiva de la agenda setting, podemos señalar que el tono positivo de los medios de comunicación podría influir en una evaluación pública favorable del tema (Capriotti, 2012). Por consiguiente, las televisiones analizadas podrían contribuir a influir positivamente también en la evaluación pública de Barcelona en relación al ámbito más social.

En definitiva, la imagen positiva de Barcelona mostrada en las tres televisiones analizadas ayuda a posicionar la marca de Barcelona en el mercado turístico de Corea del Sur, puesto que crea un impacto positivo en los coreanos. Se relaciona la ciudad sobre todo con el deporte y la cultura que son dos atributos muy eficientes para una capital pues tienen connotaciones positivas que suman atractivo turístico.

Pero la imagen de Barcelona en Corea del Sur no se limita a éstos ámbitos solamente sino también al reconocimiento de la excelencia de su gastronomía y a su entusiasta celebración de eventos que promueven la tecnología, como el Mobile World Congress. Por lo tanto, construir una imagen positiva en los campos menos explorados, menos "noticiables" para las televisiones públicas coreanas, como el político, el económico o el internacional, basados en una estrategia de comunicación más allá de la buena percepción del ámbito cultural, sería una buena manera de atraer a más turismo coreano a Barcelona.

De este estudio se desprende también que hay noticias negativas sobre Barcelona (terrorismo, robos y la confusión que genera el movimiento independentista catalán) y que, aunque porcentualmente, son menos que las positivas, su alto grado de espectacularidad puede perjudicar la imagen que de Barcelona se creen los espectadores de las tres televisiones públicas coreanas. La actividad turística es muy sensible a cualquier situación que afecte a la seguridad del turista. Esto puede dar una percepción negativa a los viajeros coreanos que quieren viajar a Barcelona, tal y como expresan García y Serrano (2018).

\section{Referencias Bibliográficas}

[1] Almeida García, F. y Jiménez Serrano, S. (2018). "Turismo y terrorismo. Crisis y medios de comunicación". Investigaciones Turísticas, (16), 23-45.

[2] Anholt, S. (2011). "Beyond the Nation Brand: The Role of Image and Identity in International Relations". Exchange: The Journal of Public Diplomacy: Vol. 2:1, 1. https://surface.syr.edu/exchange/vol2/iss1/1 
[3] Aranda, D., Sánchez Navarro, J., Martínez Cerdá, J. F. y Meneses, J. (2018). "The impact of digital practices on the perception of risks and benefits of digital gaming". Catalan Journal of Communication \& Cultural Studies, 10, 2.

[4] Beerli, A. y Martín J. D. (2004). "Tourist's characteristics and the perceived image of tourist destinations: a quantitative analysis - a case study of Lanzarote, Spain". Tourism Management, vol. 25, 623636.

[5] Camprubi, R., Guía, J. y Comas, J. (2009). "La formación de la imagen inducida: un modelo conceptual". Revista Pasos, 7(2), 255-270.

[6] Capriotti, P. (2012). "Las Vegas en Los Monegros: Evaluating the mass media coverage of the social and economic impact of a business project from a corporate communication perspective", Estudios sobre el Mensaje Períodistico, Vol. 18 Núm. 1, 305-320.

[7] Cebrián Herreros, M. (2004). La información en televisión, obsesión mercantil y política. Editorial Gedisa, Barcelona, Spain.

[8] Gartner, W. C. (1993). "Imagen formation process". Journal of Travel and Tourism Marketing, 2 (273), 191-215.

[9] Gunn, C. A. (1972). Vacation scape: Designing tourist regions. Austin: University of Texas.

[10] Gutiérrez, H.S. y Bosque, I. R. (2010). "Los factores estímulo y personales como determinantes de la formación de la imagen de marca de los destinos turísticos: un estudio aplicado a los turistas que visitan un destino vacacional". Cuadernos de Economía y Dirección de la Empresa, Vol. 13. Núm 43. 37-63 DOI: 10.1016/S1138-5758(10)70009-8

[11] Hamborg, F., Donnay, K. y Gipp, B. (2019). "Automated identification of media bias in news articles: an interdisciplinary literature review". Int J Digit Libr 20, 391-415.

[12] Han, D. (2018): Fall in love with España, ten times more in seven years. Hankyung. https://www.hankyung.com/it/article/201810205475v

[13] Holsti, O. R. (1969). Content analysis for the social sciences and humanities. Reading, MA: Addisson, Wesley.

[14] ICCA (2018). Ranking mundial de Congresos internacionales. Disponible en https://www.iccaworld. org/npps/

[15] Instituto Nacional de Estadística. (2019). España en cifras 2019. http://www.ine.es/prodyser/espa_cifras/2019

[16] Jacobsen, J.K.S., Munar, A.M. (2012) "Tourist Information Search and Destination Choice in a Digital Age", Tourism Management Perspectives 1: 39-47.

[17] Kapuscinski, G. y Richards, B. (2016). "News framing effects on destination risk perception". Tourism Management, Vol 57, 234-244.

[18] Kutlu, D., Disli, B. y Ayyildiz, H. (2018). "The effect of the online news on Tourism". Journal of Social Sciences, 17(1), 169-175.

[19] La Vanguardia. (2014). Corea del Sur se enamora España por un programa de televisión. La Vanguardia. Recuperado de https://www.lavanguardia.com/viajes/20140529/54409425757/corea-del-surse enamora-espana-programa-television.html

[20] La Vanguardia (2019). Catalunya mantiene el papel de locomotora de España en el 2018, La vanguardia, Recuperado de https://www.lavanguardia.com/economia/20190429/461934212168/cataluna-madrid-pib-crecimiento-economia.html

[21] Lee, B. K, Lee, C. K y Lee, J. (2013). "Dynamic nature of destination image and influence of tourist overall satisfaction on image modification". Journal of travel research, vol. 53,2, 239-251.

[22] Liu, X, Mehraliyev, F, Liu, C. y Schuckert, M. (2019). "The roles of social media in tourists' choices of 
travel components", Tourist Studies, Vol 20(1), 27-48.

[23] Maite Moyá, R. (2016). Habilidades comunicativas y comunicación política. Tesis doctoral, Universidad Miguel Hernández, Spain.

[24] McCombs, M. (2015). The agenda setting role of the news media. In an Integrated Approach to Communication Theory and Research, Kristen Eichorn andDon Stacks, eds., Chapter 8. New York: Routledge. DOI: 10.1016/B978-0-08-097086-8.95007-4

[25] McCracken, W. J. (1987). "Australia and Australians: View from New York Times", Journalism Quarterly, Vol. 64, issue 1, 183-187.

[26] Meijer, M. y Kleinnijenhuis, J. (2006). "Issue news and corporate reputation: applying the theories of agenda setting and issue ownership in the field of business communication". Journal of Communication, 56 (3), 543-559.

[27] Montemayor Ruiz, F. J. (2013). "Marketing experiencia en formato digital y en alta resolución: un nuevo paradigma en la retransmisión televisiva de los eventos". Revista de Comunicación Vivat Academia, $\mathrm{N}(125), 17-35$.

[28] Morales Colipe, G. (2016). "Estudio del tratamiento periodístico del acontecer sociopolítico en noticias de televisión". Revista de ciencias humanas y sociales, N. Extra 10, 304-325.

[29] Neuendorf, K. (2002). The content analysis guidebook. Cleveland state university, USA: SAGE.

[30] Rubio García, R. (2014). "Twitter and the Agenda setting theory: Messanges from the digital public opinion". Estudios sobre el mensaje periodístico. 20(1), 249-264.

[31] Sabrina Koziner, N. (2013). "Antecedentes y fundamentos de la teoría del framing en comunicación", Austral comunicación, Vol 2(1), 1-25.

[32] Schemer, C. (2012). "The influence of News Media on Stereotypic Attitudes Toward Immigrants in a Political Campaign". Journal of Communication, 62(5), 739-757.

[33] Stylos, N., Vassiliadis, C. A., Bellou, V. y Aandronikidis, A. (2016). "Destination images, holistic image and personal normative beliefs: Predictors of intention to revisit a destination". Tourism Management, V.53, 40-60.

[34] Zhang, H., XU, F., Leung, H. y Cai, L. A. (2016). "The influence of Destination-Country Image on Prospective Tourists 'Visit Intention: Testing Three Competing Models". Asia Pacific Journal of Tourism Research, 21(7), 811-835.

\section{Notas al final}

(1) Es un programa de telerrealidad que muestra a unos abuelos viajando a Barcelona y disfrutando de la comida tradicional y de las atracciones turísticas de la ciudad.

(2) Youn's Kitchen (TVN, mayo de 2017), Battle Trip: Barcelona (KBS, noviembre de 2018), Boys on the line: Barcelona (MBC, julio de 2018), Walking into the world: Barcelona (KBS, febrero de 2013), Korean hostel in spain (TVN, marzo de 2018), Themes around the World: Barcelona (EBS, abril de 2014), etc.

(3) KBS: Koean Broadcasting System, MBC: Munhwa Broadcasting Corporation, SBS: Seoul Broadcasting System. Según Korea Press Foundation, KBS, MBC y SBS son las tres únicas televisiones públicas de Corea del Sur que reciben financiación de los contribuyentes. Fueron fundadas: 3 de marzo de 1973 - KBS, 21 de febrero de 1961 - MBC y 9 de diciembre de 1991 - SBS. Recuperado el 25 de enero de 2020 de http:// www.presskorea.or.kr/index.php

(4) La traducción de los titulares en coreano es de uno de los autores del trabajo, Sin Gyu Kang.

(5) Los atentados del 17 de agosto de 2017 fueron dos ataques terroristas que se desarrollaron en las ciudades de Barcelona y Cambrils en la comunidad autónoma de Cataluña. 
(6) Según el Periódico (2019), Hye-won Kim, alto cargo del gobierno de Corea del Sur, resultó gravemente herida la noche del 23 de junio de 2019 por el tirón de un ladrón en Barcelona, falleciendo el 27 de junio. Su muerte ocasionó muchas noticias con tono negativo en 2019.

(7) Imagen recuperada de : https://www.kbs.co.kr (KBS), https://www.imbc.com (MBC), https://www. sbs.co.kr (SBS). 